\title{
Professor Howard A. Morris
}

\section{E. Cavalier ${ }^{1}$}

Received: 13 May 2019 / Accepted: 14 May 2019 / Published online: 21 June 2019

(C) International Osteoporosis Foundation and National Osteoporosis Foundation 2019

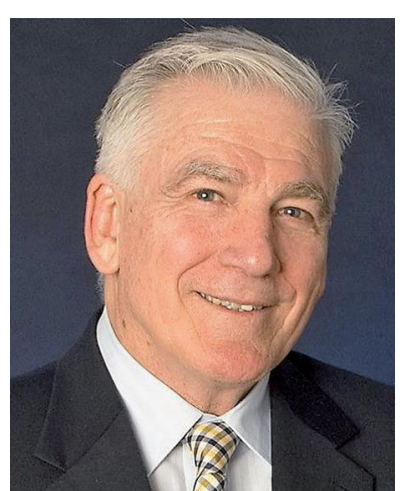

Howard A. Morris, PhD, FAACB, FFSc (RCPA), President of the International Federation of Clinical Chemistry and Laboratory Medicine (IFCC), passed away suddenly on April 18, 2019, in Kazakhstan, where he was lecturing as an IFCC Visiting Lecturer.

Professor Morris held a joint appointment as Professor of Medical science in the School of Pharmacy and Medical Sciences at the University of South Australia and as a clinical scientist in chemical pathology at South Australia Pathology in Adelaide, Australia.

He focused his research on the pathophysiology of metabolic bone disease and on the anabolic action of vitamin $\mathrm{D}$ on bone metabolism. He was notably awarded the Louis Avioli Memorial Lectureship in 2009 for his work on this topic by the ASBMR. Professor Morris has made significant contributions to science, with more than 200 publications, more than 9000 citations and a h-index of 55.

Howard Morris has worked very hard during his entire career to set the standards of laboratory medicine at their highest levels. Among others, he was convinced by the added value of the collaboration between scientific societies. He was thus a major contributor to the success of the IOF-IFCC Working Group on standardization of bone turnover markers, which he led from 2012 to 2017 , before becoming President of the IFCC. Under his chairmanship, the IOF-IFCC Working Group has published important guidelines on bone markers and on their standardization. These papers have been cited more than 600 times and have paved the way for a significant improvement of the clinical use of bone biomarkers.

We will all miss his deep knowledge and expertise, and also his optimism, his friendliness, his humility, and his big deep sound laugh. All our thoughts go for his wife, Dr. Helen Martin, and all his family.

Pulisher's note Springer Nature remains neutral with regard to jurisdictional claims in published maps and institutional affiliations
This obituary is written on behalf of the IOF-IFCC Committee for Bone Standardization

\section{E. Cavalier}

Etienne.cavalier@chuliege.be

1 Clinical Chemistry, University of Liege, Liège, Belgium 